\title{
EXPERIÊNCIA DOS ESTUDANTES DE ENGENHARIA CIVIL COM A REALIDADE SANITÁRIA EM UM CONJUNTO DE CASAS POPULARES
}

\author{
Lilyanne Rocha Garcez - lilyannegarcez@gmail.com \\ Alice Barroso Miranda - alice.barroso.miranda@gmail.com \\ Ellem Cristiane Moraes de Sousa Contente-ellem_cont@hotmail.com \\ Faculdade de Tecnologia, Universidade Federal do Amazonas \\ Av. General Rodrigo Octavio Jordão Ramos, 1200 - Bairro: Coroado I \\ CEP 69067-005 - Manaus - Amazonas
}

\begin{abstract}
Resumo: Benefícios associados à implantação de infraestrutura sanitária podem reduzir impactos em diversos aspectos sociais, ambientais $e$ de desenvolvimento em uma comunidade. Diante disso, este estudo foi desenvolvido com o objetivo de analisar aspectos sanitários a partir do levantamento de variáveis do saneamento em um conjunto de casas populares no Conjunto Cidadão X, localizado na área do Parque Riachuelo II, Município de Manaus - AM. O trabalho partiu da elaboração de matriz de indicadores do saneamento básico e da formulação de questionário base que expusesse quantitativamente os dados encontrados. A partir das ações realizadas foi possível aos estudantes de engenharia civil compreender a realidade em relação ao saneamento e analisar algumas metas de salubridade, destacando que o conjunto foi construído pela prefeitura municipal com sistemas de água, esgoto e coleta de resíduos em funcionamento, no entanto foi observado que a falta de orientação técnica para os moradores pode propiciar inúmeros problemas à comunidade, ao considerar a eficiência e eficácia dos sistemas existentes.
\end{abstract}

Palavras-chave: Indicadores. Diagnóstico sanitário. Casas Populares.

\section{INTRODUÇÃO}

Durante as últimas décadas do século XX, a Amazônia passou por mudanças estruturais provenientes do plano de integração nacional resultando que alguns municípios da região cresceram de forma desordenada e muitos aspectos ganham evidência no município de Manaus, especialmente nas áreas periféricas. (NOGUEIRA et al., 2007). Becker (2005) aponta que a Amazônia teve a maior taxa de crescimento urbano do país e o censo de 2010 assinala que $70 \%$ da população na Região Norte estão localizados em núcleos urbanos, embora muitos destes, carentes dos serviços básicos de saneamento.

$\mathrm{O}$ acesso aos serviços de saneamento básico representa uma questão central para o desenvolvimento das cidades brasileiras, principalmente em áreas periféricas, que comumente são desamparadas nestes aspectos, refletindo na saúde e qualidade do meio ambiente (PEREIRA, 2017). A Lei $\mathrm{n}^{\circ} 14.026$ de 2020 (BRASIL, 2020) que atualiza o marco legal do saneamento estabelece que os serviços de saneamento básico devem ter universalização do acesso. Perante este cenário, traz-se a realidade o Conjunto Cidadão X, situado no Parque Riachuelo II, Zona Oeste de Manaus, que surgiu em 1997 em decorrência da ocupação de terras próximas ao aeroporto da cidade, chamada "Gleba Florestal", com população estimada de 4.259 habitantes (IBGE, 2010). 
O Conjunto Cidadão X é reconhecido pela prefeitura pelo nome "Conjunto Viver Melhor I - Cidadão X - Gleba Florestal" - conforme a Relação Geral dos Conjuntos da Superintendência Estadual de Habitação - SUHAB. Foi executado pela Prefeitura durante quatro anos com o intuito de melhorar a habitação na região, porém, ainda existem vários aspectos sanitários que precisam ser analisados e aprimorados.

Nesse contexto, este trabalho buscou envolver estudantes de graduação na avaliação das condições dos serviços básicos de saneamento, contemplando os aspectos do abastecimento de água, esgotamento sanitário e manejo dos resíduos sólidos do Conjunto. Assim, o objetivo é apresentar a experiência advinda da relação do estudante de engenharia civil com os aspectos sanitários do conjunto habitacional do Parque Riachuelo II, construído e entregue pela prefeitura municipal com sistemas de água, esgoto e coleta de resíduos em funcionamento, analisando aspectos voltados a operacionalidade dos sistemas por parte dos moradores e suas possíveis consequências para a população em geral.

\section{MATERIAIS E MÉTODOS}

Para alcançar o objetivo da pesquisa foram realizadas duas etapas que consistiram em: (i) construir matriz modelo de indicadores e (ii) elaborar questionário e aplicar aos moradores/usuários de maneira a correlacionar e aproximar elementos da teoria com o nível de conhecimento sobre o contexto sanitário na área de estudo.

Os procedimentos metodológicos para o desenvolvimento das atividades envolveram os instrumentos de coleta e análise de dados: (i) levantamento bibliográfico a partir de fontes formais (livros, revistas, estudos, relatórios e artigos que se relacionam, direta ou indiretamente com a área de pesquisa); (ii) construção de matrizes de indicadores com base no levantamento bibliográfico; (iii) questionário aplicado aos comunitários com perguntas fechadas, as quais tratam de aspectos que foram desde informações básicas do saneamento até o contato com a realidade do local.

\section{1 Área de estudo}

A ocupação territorial do local que hoje é conhecido como comunidade Parque Riachuelo II teve início em medos de 1997, mas somente em 2002 o local começou a ser explorado. A comunidade inicialmente se expandiu sem qualquer auxílio público e infraestrutura para as famílias onde muitas viviam em condições precárias e em áreas de risco. Posteriormente, foi construído o Conjunto Cidadão X dentro da comunidade Parque Riachuelo II e de acordo com Relação Geral dos Conjuntos da SUHAB foi executado pela Prefeitura em quatro anos (período de 2010 a 2014) com o intuito de melhorar a habitação na região, no qual foram construídas 310 unidades em 2010, 250 em 2011, 376 em 2012, 165 em 2013 e 186 em 2014. Assim, o local utilizado neste estudo foi o Conjunto Cidadão X.

\subsection{Construção da Matriz de Indicadores}

A partir do levantamento bibliográfico elaborou-se matrizes para o sistema sanitário básico, composto por: abastecimento de água, esgoto sanitário e gerenciamento de resíduos sólidos. Cada indicador foi baseado em uma área específica que serviu como premissa para os indicadores e subindicadores, dessa forma cada componente apresenta as seguintes dimensões: (1) Técnica; (2) Social/Educação; (3) Governança (Política e Recursos Financeiros); (4) Ambiental/Ecológica; sendo a última presente na matriz do esgoto sanitário e no gerenciamento de resíduos sólidos.

A dimensão Técnica, subsequentemente com seus indicadores e subindicadores, propõem a análise da estruturação dos sistemas como suas condições de acessibilidade na comunidade 
e a existência de equipamentos básicos que suportam o funcionamento do serviço, além de avaliar como esses serviços chegam em cada residência da comunidade com o acesso à água tratada, ao tratamento de águas residuárias e a presença da coleta de resíduos.

As dimensões Social/Educação ajudaram a fomentar como os fatores sociais e educacionais se interligam pela forma como os moradores recebem e tratam esses serviços, desde o entendimento básico da importância de ter água potável, do tratamento das águas residuárias e de saber manejar seus resíduos.

Quanto as dimensões Governança (Política e Recursos Financeiros), buscou-se uma análise de como a tarifação desses serviços podem alterar a forma que a comunidade trata seus subprodutos (água, esgoto, resíduo) a fim de fomentar breve discussão acerca das problemáticas quando o assunto é tarifação de serviços públicos e cumprimento de normas e legislação sobre o adequado cumprimento a estes serviços.

Por último, a dimensão Ambiental/Ecológica propõe a análise ambiental nas questões relacionadas ao descarte do esgoto sanitário e dos resíduos sólidos, tendo como base a Lei de Diretrizes Nacionais para o Saneamento e a Política Nacional de Resíduos Sólidos.

\subsection{Aplicação do questionário}

Seguindo as diretrizes propostas pelas matrizes de cada sistema do saneamento básico e após consulta de informações com os líderes comunitários, buscou-se focar em pontos principais para a elaboração de um questionário e que as respostas pudessem orientar com base em informações antecedentes, portanto o questionário foi baseado em quatro pontos principais: (1) Dados socioeconômicos, (2) Acesso à água potável; (3) Esgotamento sanitário, (4) Gerenciamento de Resíduos Sólidos. Ao total, 46 questionários foram respondidos.

\section{RESULTADOS}

A concepção do Conjunto Cidadão X, em 2010, foi uma proposta feita pelo Poder Público e se deu por meio da Lei Municipal No 846 de 2005 (MANAUS, 2005) que já definia a Área de Especial Interesse Social (AEIS) Conjunto Habitacional Cidadão. Posteriormente, o amparo legislativo relacionado às AEIS sofreu atualizações, ganhando novos instrumentos aprovadas em outros Decretos e Leis posteriores. Assim, o conjunto faz parte da Área de Especial Interesse Social Cidadão X - AEIS Cidadão X.

De acordo com a Associação dos Amigos do Cidadão X a infraestrutura de serviços de abastecimento de água do Conjunto Cidadão X é atendida por sistema independente que utiliza a exploração de um manancial subterrâneo explorado por poço artesiano profundo. $\mathrm{O}$ sistema de esgotamento sanitário é coletivo, constituído por coleta, transporte e tratamento, ambos operados pela Concessionária de Água e Esgotos que atua na cidade de Manaus. Quanto aos Resíduos Sólidos gerados no Conjunto, $100 \%$ das residências são atendidas pela rota de coleta a cargo da Secretaria Municipal de Limpeza Urbana. A coleta é realizada em seis dias da semana (de segunda-feira aos sábados) por todo o sistema viário. A maioria das residências possuem sua própria lixeira de acondicionamento dos resíduos sólidos para coleta.

\subsection{Matriz de Indicadores}

A matriz de indicadores elaborada para a realização do diagnóstico foi construída a partir das áreas do abastecimento de água, esgotamento sanitário e resíduos sólidos, conforme Quadro 1. Observou-se um conjunto de indicadores diretamente e transversalmente ligados ao tema, dos quais foram selecionados 28 (vinte e oito) indicadores de critérios sanitários, bem como um elenco de 67 (sessenta e sete) subindicadores aplicados a realidade do Conjunto Cidadão X. A matriz foi concluída contendo, além dos indicadores, 21 (vinte e um) 


\section{COBENGE C. COBENCE $2020 \begin{aligned} & \text { de Educaçāo em Engenharia } \\ & \text { da ABENGE }\end{aligned}$}

\section{"Os desafios para formar hoje o engenheiro do amanhã"}

subindicadores para área de abastecimento de água (Quadro 2), 24 (vinte e quatro) subindicadores para área de esgotamento sanitário (Quadro 3) e 22 (vinte e dois) subindicadores para o gerenciamento dos resíduos sólidos (GRS) (Quadro 4).

Quadro 1: Questionamentos que direcionaram a elaboração da matriz de indicadores por área do saneamento básico.

\begin{tabular}{|c|c|c|}
\hline Área & Dimensão & Pergunta-chave \\
\hline \multirow{4}{*}{$\begin{array}{l}\text { Abastecimento } \\
\text { de água }\end{array}$} & 1. Técnica & Abarca aos princípios básicos de abastecimento de água? \\
\hline & 2. Social/Educação & Existe inserção do usuário na gestão dos serviços? \\
\hline & \multirow{2}{*}{$\begin{array}{l}\text { 3. Governança (Política } \\
\text { e Recursos Financeiros) }\end{array}$} & $\begin{array}{l}\text { De onde provém os recursos financeiros para manutenção e } \\
\text { expansão do sistema? }\end{array}$ \\
\hline & & Está em consonância com as políticas públicas? \\
\hline \multirow{6}{*}{$\begin{array}{l}\text { Esgotamento } \\
\text { sanitário }\end{array}$} & 1. Técnica & $\begin{array}{l}\text { Abarca os princípios básicos de rede de coleta e tratamento } \\
\text { de esgoto sanitário? }\end{array}$ \\
\hline & 2. Social/Educação & Existe inserção do usuário na gestão dos serviços? \\
\hline & \multirow{2}{*}{$\begin{array}{l}\text { 3. Governança (Política } \\
\text { e Recursos Financeiros) }\end{array}$} & $\begin{array}{l}\text { De onde provém os recursos financeiros para manutenção e } \\
\text { expansão do sistema? }\end{array}$ \\
\hline & & Está em consonância com as políticas públicas? \\
\hline & \multirow{2}{*}{ 4. Ambiental/Ecológica } & Exerce algum impacto ambiental mínimo? \\
\hline & & Existe relação do sistema de esgoto com a drenagem local? \\
\hline \multirow{6}{*}{$\begin{array}{c}\text { Resíduos } \\
\text { Sólidos (RS) }\end{array}$} & 1. Técnica & Abarca os princípios básicos de GRS? \\
\hline & 2. Social/Educação & Existe inclusão Social no GRS? \\
\hline & \multirow{3}{*}{$\begin{array}{l}\text { 3. Governança (Política } \\
\text { e Recursos Financeiros) }\end{array}$} & Está em consonância com a PNRS? \\
\hline & & Existe capacidade de pagamento pela população? \\
\hline & & $\begin{array}{l}\text { A associação de moradores possui ligação com os } \\
\text { catadores? }\end{array}$ \\
\hline & 4. Ambiental/ Ecológica & Exerce algum tipo de impacto ambiental mínimo? \\
\hline
\end{tabular}

Quadro 2. Matriz de indicadores e subindicadores para diagnóstico referente ao abastecimento de água

\begin{tabular}{|c|c|c|}
\hline Área & Indicador & Subindicador \\
\hline \multirow{22}{*}{ 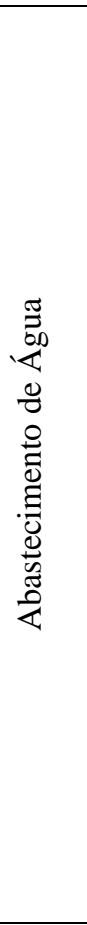 } & \multirow{5}{*}{$\begin{array}{l}\text { 1.1. Estruturas do } \\
\text { sistema de } \\
\text { abastecimento de } \\
\text { água }\end{array}$} & 1.1.1. Condições de acessibilidade de abastecimento \\
\hline & & 1.1.2. Fornecimento de água sem interrupções ou racionamento \\
\hline & & 1.1.3. Água dentro dos padrões de potabilidade \\
\hline & & 1.1.4. Presença e manutenção de reservatórios de água \\
\hline & & 1.1.5. Taxa de cobertura do abastecimento de água pela concessionária \\
\hline & \multirow{4}{*}{$\begin{array}{l}\text { 1.2. Atendimento à } \\
\text { comunidade }\end{array}$} & 1.2.1. Acesso a água tratada \\
\hline & & 1.2.2. Condições para atender demanda adicional \\
\hline & & 1.2.3. Presença de poços artesianos \\
\hline & & 1.2.4. Presença de nascentes \\
\hline & \multirow{2}{*}{$\begin{array}{l}\text { 2.1. Níveis de } \\
\text { escolaridade }\end{array}$} & 2.1.1. Nível de escolaridade \\
\hline & & 2.1.2. Influência no entendimento sobre a importância de ter água tratada \\
\hline & \multirow{2}{*}{ 2.2. Uso do Sistema } & 2.2.1. Desvios irregulares \\
\hline & & 2.2.2. Contaminação por desvios irregulares \\
\hline & \multirow{2}{*}{ 2.3. Renda per capita } & 2.3.1. Renda per capita \\
\hline & & 2.3.2. Influência da renda atrelada à prestação serviço de abastecimento \\
\hline & \multirow{3}{*}{$\begin{array}{c}\text { 2.4. Inclusão de } \\
\text { ações de Educação } \\
\text { Ambiental }\end{array}$} & 2.4.1. Material informativo sobre o abastecimento de água \\
\hline & & 2.4.2. Material informativo sobre a economia do consumo de água \\
\hline & & 2.4.3. Realização de eventos locais com a temática ambiental \\
\hline & 3.1. Tarifação & 3.1.1. Tarifa de serviços de abastecimento de água \\
\hline & \multirow{3}{*}{ 3.2. Fiscalização } & 3.2.1. Fiscalização quanto o cumprimento de normas e portarias \\
\hline & & 3.2.2. Licenciamento para funcionamento adequado da concessionária \\
\hline & & 3.2.3. Utiliza mão-de-obra local \\
\hline
\end{tabular}
Fonte: Próprios autores 


\section{IS COBENCE (C) COBENCE 2020

"Os desafios para formar hoje o engenheiro do amanhã"

Quadro 3. Matriz de indicadores e subindicadores para diagnóstico referente ao esgotamento sanitário

\begin{tabular}{|c|c|c|}
\hline Área & Indicador & Subindicador \\
\hline & \multirow{2}{*}{$\begin{array}{l}\text { 1.1. Condições das } \\
\text { estruturas do sistema } \\
\text { de rede de esgoto }\end{array}$} & $\begin{array}{l}\text { 1.1.1. Existência de condutos, instalações ou equipamentos destinados a coletar, } \\
\text { transportar, condicionar e encaminhar o esgoto sanitário }\end{array}$ \\
\hline & & 1.1.2. Taxa de cobertura de esgotamento sanitário da comunidade \\
\hline & \multirow{3}{*}{ 1.2. Endemias } & 1.2.1. Endemias relacionadas à falta de tratamento de esgoto \\
\hline & & 1.2.2. Riscos relacionados à falta ou precariedade do serviço \\
\hline & & $\begin{array}{l}\text { 1.2.3. Populações sob risco relacionados à ausência de condições adequadas de } \\
\text { uma rede coletora de esgoto }\end{array}$ \\
\hline & $\begin{array}{l}\text { 1.3. Atendimento à } \\
\text { comunidade }\end{array}$ & 1.3.2. Acesso ao tratamento de esgoto \\
\hline & \multirow{3}{*}{$\begin{array}{l}\text { 2.1. Nível de } \\
\text { escolaridade }\end{array}$} & 2.1.1. Nível de Escolaridade \\
\hline & & 2.1.2. Influência no entendimento sobre a importância do tratamento de esgoto \\
\hline & & 2.1.3. As pessoas entendem o que é um sistema de tratamento de esgoto \\
\hline & \multirow{3}{*}{ 2.2. Uso do sistema } & 2.2.1. Presença de sistema fossa séptica \\
\hline & & 2.2.2. Presença de caixas de gordura e caixas de inspeção nas residências \\
\hline & & 2.2.3. Lançamento de efluentes em corpos d'água \\
\hline & \multirow[b]{2}{*}{ 2.3. Renda per capita } & 2.3.1. Renda per capita \\
\hline & & $\begin{array}{l}\text { 2.3.2. Influência da renda atrelada a implantação dos itens de responsabilidade do } \\
\text { cidadão }(\mathrm{CG}, \mathrm{CI})\end{array}$ \\
\hline & \multirow{2}{*}{$\begin{array}{l}\text { 2.4. Inclusão de ações } \\
\text { de Educação }\end{array}$} & 2.4.1. Material informativo sobre o sistema de esgotamento sanitário \\
\hline & & 2.4.2. Realização de eventos locais com a temática ambiental \\
\hline & \multirow{2}{*}{$\begin{array}{l}\text { 3.1 Tarifação e } \\
\text { Projetos }\end{array}$} & 3.1.1. Existência de tarifação sobre os serviços de saneamento \\
\hline & & 3.1.2. Existência de projeto para expansão da rede de esgoto coletora \\
\hline & \multirow{2}{*}{ 3.2. Fiscalização } & 3.2.1. Fiscalização quanto o bom cumprimento de normas e portarias \\
\hline & & 3.2.2. Licenciamento para funcionamento adequado da empresa concessionária \\
\hline & \multirow{2}{*}{$\begin{array}{l}\text { 4.1. Disposição dos } \\
\text { esgotos sanitários }\end{array}$} & 4.1.1. Local de disposição do esgoto gerado \\
\hline & & 4.1.2. Despejo em igarapés/cursos de rio \\
\hline & \multirow{2}{*}{$\begin{array}{l}\text { 4.2. Dispositivos de } \\
\text { drenagem }\end{array}$} & 4.2.1. Existência de dispositivos de drenagem \\
\hline & & 4.2.2. Lançamento de efluentes diretamente na rede de drenagem \\
\hline
\end{tabular}
Fonte: Próprios autores

Quadro 4. Matriz de indicadores e subindicadores para

diagnóstico referente ao gerenciamento de resíduos sólidos

\begin{tabular}{|c|c|c|}
\hline Área & Indicador & Subindicador \\
\hline \multirow{22}{*}{ 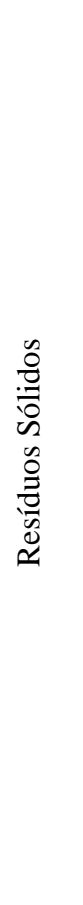 } & \multirow{2}{*}{$\begin{array}{l}\text { 1.1. Princípios da } \\
\text { Tecnologia }\end{array}$} & 1.1.1. Existência de veículo coletor específico e apropriado \\
\hline & & 1.1.2. Utiliza mão-de-obra local \\
\hline & \multirow{2}{*}{$\begin{array}{l}\text { 2.1. Inserção de } \\
\text { catadores e artesãos }\end{array}$} & 2.1.1. Existência de catadores organizados (cooperativas, associações etc.) \\
\hline & & 2.1.2. Existência de artesãos que utilizam resíduos pós-consumo \\
\hline & \multirow{2}{*}{ 2.2. Renda Per Capita } & 2.2.1. Renda per capita mensal obtida pelos catadores \\
\hline & & 2.2.2. Renda obtida pelos artesãos \\
\hline & \multirow{4}{*}{$\begin{array}{l}\text { 2.3. Inclusão de ações } \\
\text { de Educação } \\
\text { ambiental }\end{array}$} & 2.3.1. Material informativo sobre o manejo de resíduos sólidos \\
\hline & & 2.3.2. Realização de eventos de capacitação de artesãos locais \\
\hline & & 2.3.3. Realização de eventos locais com a temática ambiental \\
\hline & & 3.1.1. Apresenta Fiscalização dos serviços de limpeza pública \\
\hline & \multirow{2}{*}{$\begin{array}{l}\text { 3.1. Política Nacional } \\
\text { de Resíduos Sólidos }\end{array}$} & 3.2.2. Taxa específica para o serviço de limpeza pública \\
\hline & & 3.2.2. Coleta, tratamento e disposição final auto financiada pelo município \\
\hline & $\begin{array}{l}\text { 3.2. Origem dos } \\
\text { recursos financeiros }\end{array}$ & 3.2.3. Percentual do orçamento municipal aos serviços de limpeza pública \\
\hline & 3.3. Cooperativa & 3.3.1. Cooperativa entre associação de moradores e catadores \\
\hline & \multirow{2}{*}{ 4.1. Coleta Seletiva } & 4.1.1. Existência de Coleta Seletiva no bairro \\
\hline & & 4.1.2. Abrangência da coleta seletiva \\
\hline & \multirow{6}{*}{ 4.2. Coleta de RS } & 4.2.1. Eficiência da coleta \\
\hline & & 4.2.2. Satisfação da população em relação à coleta pública \\
\hline & & 4.2.3. Existência de lixeiras \\
\hline & & 4.2.4. Resíduos gerados \\
\hline & & 4.2.5. Logística Reserva \\
\hline & & 4.2.6. Geração de Resíduos Orgânicos \\
\hline
\end{tabular}

Fonte: Próprios autores 


\subsection{Diagnóstico a partir da aplicação do questionário}

Os resultados obtidos dos 46 (quarenta e seis) questionários respondidos mostram o quantitativo (barras à esquerda) e a porcentagem (barras à direita) nas Figuras de 1 a 4 para os dados socioeconômicos, sendo a Figura 1 referente ao gênero, Figura 2 a escolaridade, Figura 3 a renda e Figura 4 a quantidade de pessoas que residem na casa.

Figura 1. Quantitativo referente ao gênero

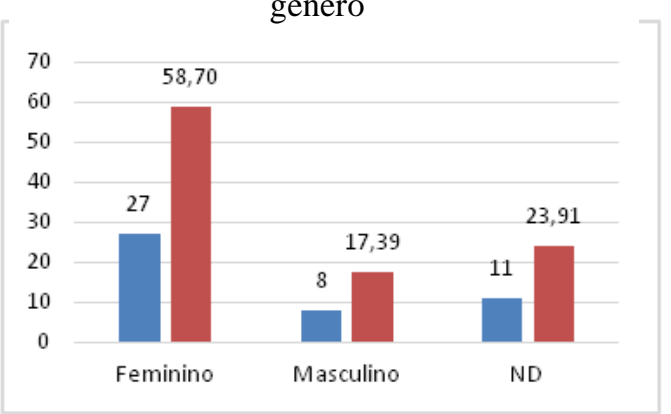

Figura 2. Quantitativo referente a escolaridade

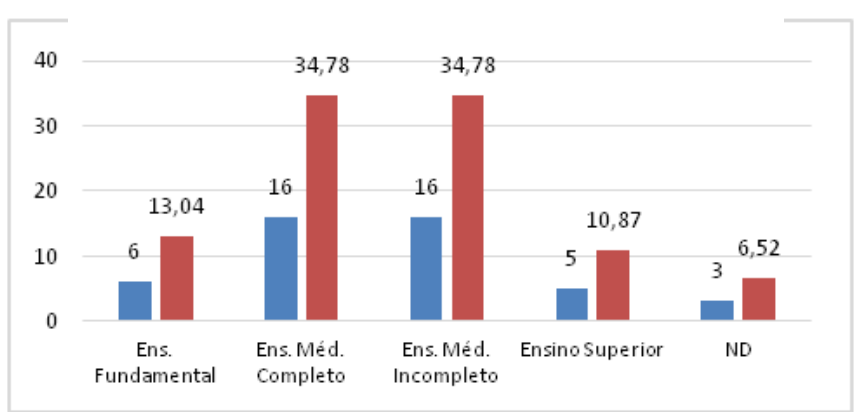

Fonte: Próprios autores

Os resultados da Figura 1 apresentam a quantidade de mulheres presentes no preenchimento do questionário que, em sua maioria são desempregadas, dependem financeiramente da renda obtida pelos maridos e trabalham diretamente nos afazeres domésticos. Quanto a escolaridade (Figura 2) é perceptível observar que $48 \%$ não possuem ensino médio completo e mais de $80 \%$ não possuem ensino superior. Nunes et al., (2017) apresenta dados de correlação entre o nível de escolaridade e aspectos sanitários no qual os déficits no âmbito sanitário são amplos e que o conhecimento de cada morador no assunto nem sempre está associado a este nível. Porém, Camello et al., (2016) aponta a necessidade de um maior investimento programas de conscientização e educação quanto ao saneamento e a saúde pública, pois o desconhecimento do tema pode trazer prejuízos à saúde do indivíduo.

Figura 3. Ouantitativo referente a renda

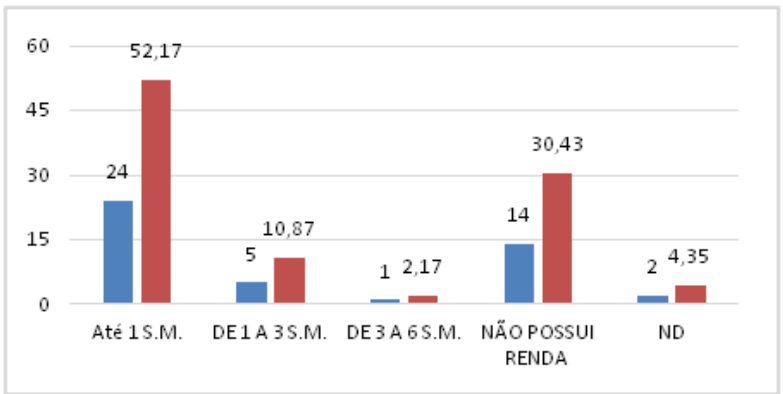

Figura 4. Quantitativo referente a quantidade de moradores na residência

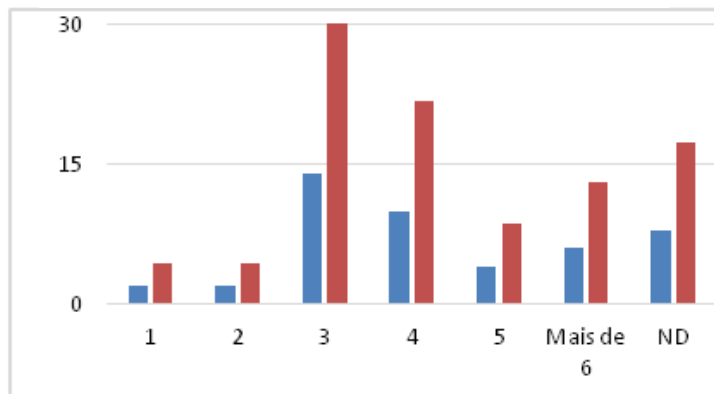

Fonte: Próprios autores

É importante destacar (Figura 3) que mais de $80 \%$ dos moradores não possuem renda ou recebem menos de um salário mínimo para a subsistência de seus familiares, reiterando que são moradores de um conjunto habitacional de casas populares. Outro aspecto relevante é que apesar da renda a maioria das residências possui entre quatro e cinco moradores (Figura 4).

Nas visitas realizadas foi possível observar que os moradores entendem, de forma geral, a necessidade do saneamento, mas acrescentam a renda como fator primordial no qual impede que sejam obrigados a pagar custos elevados por sistema eficiente de água e esgoto, tendo em vista a prioridade da família ser a alimentação. Provavelmente não há uma compreensão de que a infraestrutura sanitária pode promover saúde e padrão de vida adequado, influenciando no crescimento de maneira saudável da população (Rosa Neto et al., 2020). 
A Figura 5 demonstra o grau de satisfação com o abastecimento de água e a Figura 6 o consumo consciente dos moradores, destacando que $45 \%$ dos moradores acreditam ser importante o sistema de água potável para as residências.

Figura 5. Grau de satisfação quanto ao abastecimento de água

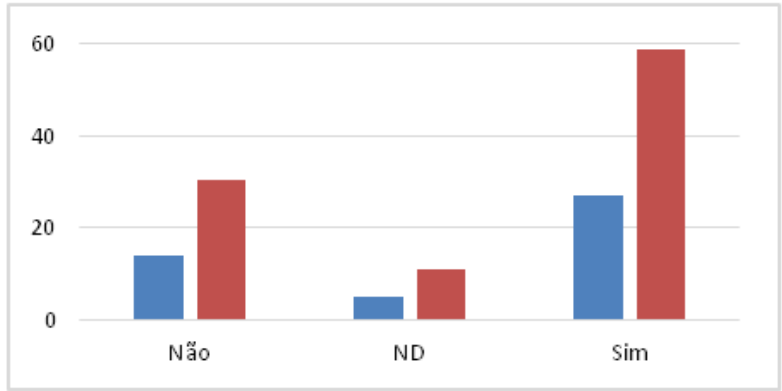

Figura 6. Índice de conscientização quanto a água potável

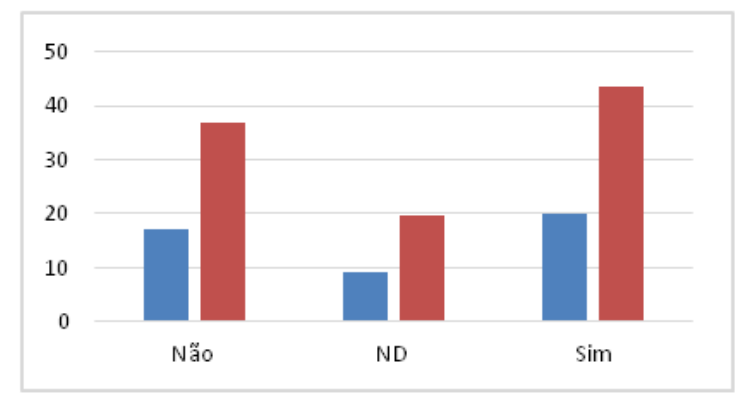

Fonte: Próprios autores

Os resultados obtidos na Figura 5 demonstram que a maioria dos moradores estão satisfeitos com a água distribuída pela concessionária da cidade, no entanto, a potabilidade da água não é exposta pelos moradores como condição relevante de avaliação do sistema, podendo tal percepção estar associada a fator econômico, ou seja, da capacidade de pagamento por parte do morador e da disponibilidade da água nas suas residências. Destacase com essas proporções que não basta somente construir infraestrutura adequada de acesso a água se não forem criados na comunidade condições e conhecimentos dos princípios básicos do saneamento e o efeito dos seus serviços.

As Figuras 7 e 8 apresentam os dados levantados quanto ao sistema de esgotamento sanitário e descrevem a satisfação e funcionamento da rede de esgoto, indicando a falta de manutenção e limpeza das caixas, por isso a geração de odor e incômodo dos moradores. Com base nas visitas realizadas observou-se que todas as residências atendidas pelo sistema possuem tratamento primário através de caixas de gordura, porém sem a utilização de caixas de inspeção. A limpeza das caixas de gordura nas moradias é de responsabilidade de cada morador e foram relatados casos de entupimento de canalizações.

Figura 7. Grau de satisfação quanto ao sistema de esgotamento sanitário

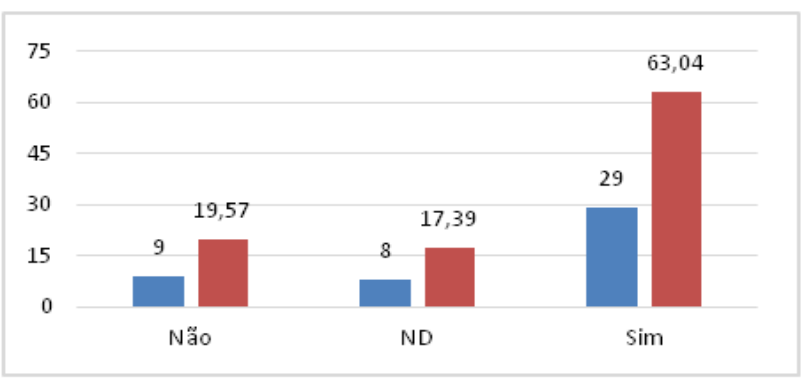

Fonte: Próprios autores

A Concessionária de Água e Esgotos informou que em algumas ruas a rede de esgoto foi executada paralela as calçadas e com a ampliação das moradias por parte dos moradores, a rede e alguns poços de visitas de esgoto foram enterrados. Ficou constatado também que algumas residências não são atendidas pela rede, resultando em utilização de formas inadequadas de esgotamento sanitário como, por exemplo, fossas rudimentares e lançamento do efluente sem tratamento prévio diretamente no solo ou no sistema de drenagem. 
As Figuras 9 e 10 demonstram o interesse em separar os resíduos para reciclagem, mas ainda não o fazem devido não ter na localidade associação ou cooperativa de catadores sendo os resíduos sólidos destinados para o aterro municipal.

Figura 9. Grau de interesse em realizar a coleta seletiva

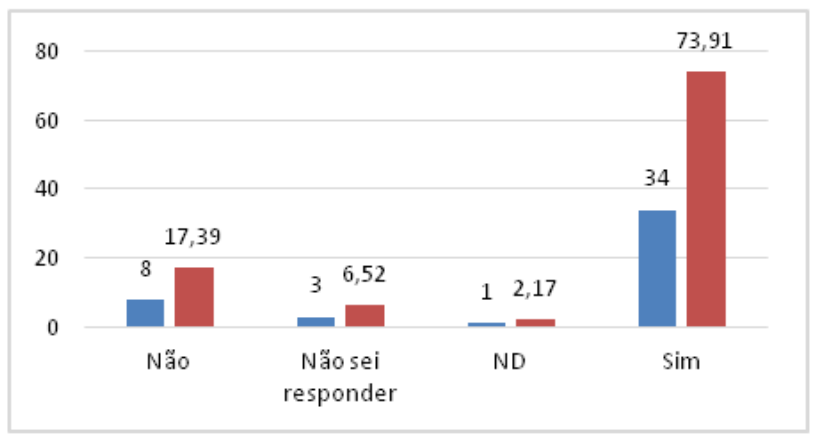

Fonte: Próprios autores

Destaca-se pela Figura 9 que a inclusão social de catadores nos programas de coleta seletiva beneficiaria o local, bem como ampliaria a valorização do catador, gerando cidadania e inclusão social. A implantação da coleta seletiva no conjunto poderia partir de abordagens e orientações para efetivar a segregação dos resíduos na fonte geradora, envolvendo um processo de mobilização social com ações e técnicas de atividades de educação ambiental, como, por exemplo, visita e orientação porta a porta, informes nas igrejas, escolas, reuniões da Associação, para incentivar a participação voluntária dos moradores.

A partir de informações da Associação dos Amigos do Cidadão X, não existe nenhuma associação ou cooperativa de catadores no conjunto, assim como não há parcerias nem atuação de nenhuma das associações, cooperativas, núcleos e grupos independentes existentes na cidade (Figura 10). Porém, de acordo com a lista de entidades de catadores em Manaus o Grupo Independente "Projeto Reciclar Dá Vida" está localizado dentro da área que compreende o Parque Riachuelo II que recebem: papel, papelão e latas de alumínio. A ideia de estabelecer uma parceria foi exposta e demonstrou-se interesse pelos moradores.

\section{DISCUSSÃO}

Os indicadores de acesso à infraestrutura sanitária levantados pelos estudantes possuem importância para avaliação do conjunto analisado ao definir perfil de ocupação que pode estar ocasionando dados nos aspectos sanitários, principalmente os que impactam diretamente os aspectos humanos. Observou-se que a dimensão social abrangendo a conscientização da população e a educação ambiental está diretamente vinculada com o tema. Foram constatadas ocorrências em que as ações dos próprios moradores (em sua maioria para resolver situações individuais e não coletivas) ocasionaram problemas e que são suas principais reclamações, como o entupimento das canalizações de drenagem e os retornos nas tubulações de esgoto.

Apesar da educação ambiental ser reconhecidamente um dos instrumentos mais relevantes no âmbito das ações de saneamento, a inexistência de intervenções conduzidas sob orientação dos programas municipais dentro do Cidadão $\mathrm{X}$ gera impacto efetivo às problemáticas existentes no campo do saneamento. Também foram sinalizados pelos estudantes as fragilidades quanto ao processo de urbanização e de acesso à infraestrutura de saneamento, sem que haja a participação popular em paralelo com a educação ambiental para esclarecimento técnico aos moradores, que geraria mudança de comportamento e, consequentemente, menos impactos negativos tanto social quanto ambiental. 
Por meio das visitas realizadas constatou-se que diversos aspectos da falta de conhecimento da população sobre temas relacionados ao saneamento e sem intervenções de educação ambiental, se cria um ciclo vicioso na comunidade onde cada morador pode tomar atitudes inadequadas que influencia a outros moradores a mesma atitude.

Um dos exemplos, pode-se citar a queima de resíduos que era um processo de destinação inadequada constantemente realizada nos primeiros anos de construção, contudo esse tipo de ação foi limitada por intervenções de fiscalização e conscientização feitas pela própria Associação de moradores no qual a prática foi modificada aos poucos e influenciada a partir da coleta ser realizada periodicamente pela prefeitura municipal.

\section{CONCLUSÕES}

Sabe-se que os indicadores são importantes instrumentos de auxílio na gestão do saneamento básico, na medida que podem subsidiar ações mais efetivas de intervenção, monitoramento e qualidade dos serviços prestados, principalmente no contexto de realidades amazônicas. Neste sentido, a pesquisa agregou elementos de análise relevantes sobre a realidade sanitária, considerando a dinâmica ocupacional e social existente no Conjunto Cidadão X. Somado a este enfoque, tem-se ainda a inserção do estudante de Engenharia Civil ao direcionar análise a partir do levantamento de dados próprios da realidade local, ou seja, possibilitando vivenciar problemáticas associadas ao contexto dos serviços de saneamento não previstos nos fluxos das etapas de planejamento, projeto, implantação e operação dos sistemas de abastecimento de água, esgotamento sanitário e resíduos sólidos.

Essa experiência foi possível, no primeiro momento, a partir da construção dos indicadores e subindicadores e, posteriormente, a abordagem acerca do cenário real levantado por meio das visitas técnicas e levantamento de dados in loco realizadas. Em segundo, a visão de uma realidade sanitária experimentada pelos estudantes de Engenharia Civil no conjunto Cidadão $\mathrm{X}$, o qual foi construído e entregue aos moradores pela gestão municipal com serviços de saneamento básico (água, esgoto e resíduos sólidos).

Assim, dentre as observações experimentadas pelos estudantes foi possível concluir que os moradores, por não possuírem aporte de conhecimento técnico do funcionamento dos sistemas de saneamento básico implantados no Conjunto, podem contribuir com inúmeros problemas de ordem coletiva tanto para a população local e de ordem ambiental. Nesse caminho, a Engenharia tem seu papel de compreender mecanismos, bem como buscar junto a Educação Ambiental fortalecer o papel de competência da população como usuário.

Outro aspecto observado foi a potencialidade de aplicação dos indicadores e seus subindicadores em aglomerados urbanos com características similares ao Conjunto, constituindo assim um instrumento de diagnóstico e planejamento para investimentos futuros em sistemas de saneamento básico, ao abordar aspectos da realidade local.

A partir do estudo realizado foi possível aos estudantes de engenharia civil compreender a realidade em relação ao saneamento e analisar metas de salubridade, visando à promoção da melhoria da qualidade de vida, garantindo a universalização, regularidade e equidade na prestação dos serviços de saneamento básico.

Tal perspectiva do estudante favorece o argumento de que a análise das dimensões sanitárias do conjunto é complexa e por isso deve combinar dados quantitativos e qualitativos bem como a interpretação dos aspectos locais. Ademais, entender as interações entre os atores sociais e os resultados que elas incorrem é mais importante do que tentar mensurar a todo custo dados em relação a sustentabilidade dos serviços de saneamento básico. Do mesmo modo, mensurar e estabelecer parâmetros de análise pode servir como uma ferramenta de gestão eficaz para diagnosticar eventuais limitações. 


\title{
REFERÊNCIAS
}

BECKER, B. K. Geopolítica da Amazônia. Estudos Avançados, São Paulo, v. 19, n. 53, 2005.

BRASIL. Lei $\mathrm{N}^{\circ}$ 14.026, de 15 de julho de 2020. Atualiza o marco legal para o saneamento básico.

CAMELlO, J. T.; CAVAGNOLLI, N. I.; SPADA, P. K. W. D. S.; POETA, J.; RODRIGUES, A. D.

Prevalência de parasitoses intestinais e condições de saneamento básico das moradias em escolares da zona urbana de Caxias do Sul, Rio Grande do Sul. Scientia Medica. 26(1): 2016.

INSTITUTO BRASILEIRO DE GEOGRAFIA E ESTATÍSTICA - IBGE. Censo Demográfico 2010: Aglomerados subnormais - Primeiros Resultados. Censo 2010.

MANAUS. Lei No 846 de 24 de junho de 2005. Dispõe sobre as Área de Especial Interesse Social previstas no Art. 105 da Lei n. 671, de 05/11/2002, e dá outras providências.

NOGUEIRA A., F. SANSON, K. PESSOA. A expansão urbana e demográfica da cidade de Manaus e seus impactos ambientais. 2007; Anais XIII Simpósio Brasileiro de Sensoriamento Remoto, Florianópolis, Brasil; p. 5427-5434.

NUNES, A. C. D.; CARVALHO NETO, E. de O.; ARAUJO, J. M. P. de; FERREIRA, I. J. S.; AMORIM, M. C. C. Percepção do Saneamento Básico por Moradores de Juazeiro-BA com Vista a Ações Educativas. REVASF. V. 7, n.13, p.06-32. 2017.

PEREIRA, A. C. Proposição de uma matriz de indicadores de sustentabilidade para avaliação do saneamento básico em comunidades rurais. 2017. 125 f. Dissertação (Mestrado em Engenharia Civil) - Universidade Federal de Viçosa, Viçosa. 2017.

ROSA NETO, F.; PIRES, M. M. de S.; BIANCO, C. D.; PIMENTA, R.; SILVA, A. P.; MARIANO, M. Saneamento Básico Inadequado Impacta no Desenvolvimento Infantil. Arquivos Catarinenses de Medicina. abr-jun; 49(2):68-81. 2020.

\section{EXPERIENCE OF CIVIL ENGINEERING STUDENTS WITH THE SANITARY RELITY OF THE SET OF POPULAR HOUSES}

\begin{abstract}
Benefits associated with the implementation of health infrastructure can reduce impacts on several social, environmental and development aspects of a community. Therefore, this study was developed with the objective of analyzing sanitary aspects from the survey of sanitation variables in a set of popular houses in Conjunto Cidadão X, Municipality of Manaus - AM. The study started from the elaboration of a matrix of indicators of basic sanitation, from the formulation of a basic questionnaire that exposed the data found quantitatively. From the study carried out, it was possible for civil engineering students to understand the reality in relation to sanitation and to analyze some health goals, highlighting that the set was built by the city hall with water, sewage and waste collection systems in operation, but the lack of technical guidance for residents can create numerous problems for the community when considering the efficiency and effectiveness of existing systems.
\end{abstract}

Keywords: Indicators. Health diagnosis. Popular houses. 